\title{
An Investigation into Pre-Service Teachers' Perceptions of Learning Primary School Science Using the Method of Problem Based Learning (PBL)
}

\author{
Musa El Sharief Mohamed ${ }^{1, *}$ \\ ${ }^{1}$ Centre for Education Programmes, The University of Trinidad and Tobago, Corinth Campus/San Fernando, \\ Trinidad and Tobago \\ *Correspondence: Centre for Education Programmes, The University of Trinidad and Tobago, Corinth Campus/San \\ Fernando, Trinidad and Tobago. Tel: 868-642-8888 Ext.31100.E-mail: musa.mohamed@utt.edu.tt
}

Received: April 22, 2015

Accepted: April 30, 2015 Online Published: May 12, 2015

doi:10.5430/wje.v5n3p44

URL: http://dx.doi.org/10.5430/wje.v5n3p44

\begin{abstract}
The aim of this study was to investigate the pre-service teachers' perceptions into learning primary school science using the method of Problem Based Learning (PBL). This learning strategy has been introduced into the B.Ed. programme at the University of Trinidad and Tobago for pre-service teachers who are expected to implement it in their teaching profession in primary school science. The research study attempted to identify the perceptions of these pre-service teachers during the learning process of PBL. Data were collected by means of semi-structured interviews with written comments and a questionnaire. The results showed that there is a general agreement among the participants that PBL is a good strategy for discovery learning and enhancing content knowledge for both the group and the individual. There were negative perceptions about the availability of time for the application of PBL in the classroom due to the short teaching periods at the primary level. The prevailing school culture of the old method of teaching was also identified as an obstacle to application.
\end{abstract}

Keywords: pre-service teachers' perception; Problem Base Learning(PBL); primary school science; semi-structured interviews; questionnaire

\section{Introduction}

The use of PBL as a learning strategy in science courses is new to the B.Ed students at the school of Cognition, Learning and Education. Since the pre-service teachers' perceptions about this learning strategy are unknown, particularly in teaching primary science, the researcher needs to discover these perceptions as compared to the traditional method of science learning to which they have been exposed throughout their entire learning process. Discovering these perceptions about PBL will result in an adjustment of instructional methods to the most effective ones appropriate to primary science teaching and learning.

For quite some time, John Dewey, Piaget and other constructivists educators have been advancing teaching methods that are more student centred than the old method of 'chalk and talk' delivery. According to Napoli (2011), "in student centred approaches: students are not considered to be empty vessels. They come with their perceptual framework. Focus is not just on what is taught but on how effective learning should be promoted..." (p. 3). Here, Napoli suggests that students always have their perceptions about learning a particular concept. In fact they may have misunderstandings of scientific concepts from their daily life experience. Therefore to dispel this perception, the effectiveness in the teaching-learning process has to be profound enough to promote authentic learning. As it relates to the teaching of science this can only be achieved when the teaching consists of a high standard of Pedagogical Content Knowledge (PCK).

The hands on, inquiry and critical thinking became a paradigm shift where science education is concerned. Although the origin of these teaching strategies cannot be traced, they have resonated with the theories advanced by the constructivists. Minner et al. (2009) stated that: 
It is difficult to exactly trace the first appearance of inquiry instruction, but it was born out of the longstanding dialogue about the nature of learning and teaching, in particular from the work of Jean Piaget, Lev Vygotsky, and David Ausubel. The work of these theorists was blended into the philosophy of learning known as constructivism (Cakir, 2008), which was then used to shape instructional materials. (p.2)

This means that learners are capable of constructing knowledge on their own given that the correct methods of inquiry and resources are provided. For teachers to adopt this shift of knowledge construction by learners, they ought to know and understand the philosophy and theory that are the driving force of these new and innovative pedagogical methods of teaching such as PBL, inquiry skills and critical thinking. Identifying the issues and examining the benefit of PBL (2011) it is stated that:

PBL draws on constructivist and social constructivist principles of learning advocating student centred engagement with course content and peer-to-peer interactions as central to the learning process. PBL is not discovery learning, case based learning, inquiry learning or project based learning. Rather PBL is learning that occurs through immersion in a specific problem that requires students to apply reasoning (p.1). It is clear from this statement that PBL is distinguished from other pedagogical methods by its unique way of problem solving. PBL is based on self directed learning (SDL) and researching to construct knowledge. Research has shown that SDL plays an important role in the ability of the student to perform. This has been reported by Walker and Lofton (2003, p.8) as cited in Ryan (1993) who argued that, "students perceived SDL as important from the onset of the study. The students' perceived ability to perform SDL increased with the use of PBL." When teachers understand these pedagogical strategies and their importance in the learning process, then and only then they will be fully committed to their implementation in their classroom.

The traditional method of teaching has long been criticised for its 'banking concept' approach "it transforms students into receiving objects. It attempts to control thinking and action, leads men and women to adjust to the world, and inhibits their creative power" (Freire, 1970, p. 77). This system has made the student into a vessel for the teacher to pour the knowledge into it. There is little or no interaction between the two parties and the system is based on a passive method of delivery. Rote and regurgitation are the features of this old teaching method hence, recalling of early learnt scientific principles would not be easy for students in their future pursuits of scientific knowledge.

Fortunately, this old traditional method of teaching is now being gradually modified by pedagogical methods which are more student-centred, particularly in the fields of medicine and science, "Problem based Learning began at McMaster University Medical School over 25 years ago. It has since been implemented in various..." (p.1) (Maricopa, n.d.). This research project intends to address the perceptions of trainee pre-service teachers towards these innovative student centred methods, in particular PBL. For this innovative learning strategy to succeed, teachers' perceptions about future implementation as a learning strategy in primary school science have to be examined. This is due to the fact that the relevance of the holistic change in education cannot be altered without the positive acceptance of the people on the ground. The existing culture of the old teaching methods is deeply rooted in the teaching of primary school science. The implementation of PBL in this culture depends on the perceptions and the enthusiasm of the B.Ed. graduates who learnt this method.

\section{Aim of the Study}

The aim of this study is to gain insight into pre-service primary school teachers' perceptions of learning primary science using the method of Problem Based Learning (PBL). Teaching of science has been done through the old method of 'jug and mug' and this had a great effect on student attitude to science. The new trend is to teach science through student centred inquiry skills, critical thinking and problem solving. Certain studies have shown that learning through PBL strategy in other subjects has produced positive results, "PBL resulted in: improved problem solving, improved time management, self learning, and improved research skills." (Bentley et al, 1999, p.1).

\section{Objectives}

- To examine pre-service teachers' early school experiences of learning science;

- To examine pre-service teachers' perceptions of learning primary school science using the method of Problem Based Learning (PBL); and

- To identify the issues that pre-service teachers faced in learning primary school science using the method of Problem based learning. 


\section{Key Research Questions}

Question 1: What are pre-service teachers' early school experiences of learning science?

Question 2: What are pre-service teachers' perceptions of learning primary school science using the method of Problem Based Learning (PBL)?

Question 3: What are the issues that pre-service teachers faced in learning primary school science using the method of Problem Based Learning (PBL)?

\section{Significance of the Study}

At the school of Cognition, Education and Learning, the B.Ed. degree programme covers many areas of student centred activities. The performance of students has a lot to do with the method of knowledge construction. The constructivist method advocates the hands-on inquiry based learning method because the students construct knowledge according to their own pace. They are afforded the opportunity to play a more active role in the way their learning process.

The learning of science itself is based on perceptions and beliefs that some students brought with them to the learning environment. For this reason, it is very important to research perceptions of students in science learning whether from the theory aspect or the method of delivery. This is more crucial in the case of pre-service teachers because their perceptions influence the way they think and the way they go about delivering their science lessons. This could also be reflected in their attitudes and values in the whole learning and teaching scenario.

Researching teacher's perception about learning science will enable understanding of the decisions they make about their classroom teaching. These decisions may affect the outcome of a specific education policy that has to be implemented in the science curriculum. If a teacher's perception is positive, then implementation of the strategy should be successful, whereas a negative perception will result in failure of the strategy implementation.

Problem Based Learning (PBL) which involves critical thinking, inquiry and solving of challenging open ended questions, is the methodology used in higher education. Teams of four to six students are given a subject specific problem to solve. The instructor acts as a facilitator and the students organize and delegate the different tasks required to solve the problem.

This research of the problem of learning primary science through the strategy of problem based learning (PBL) is based on the premise that it offers more hands-on activities to student teachers. In this way, the trainee teachers will be equipped for teaching science in a more authentic and effective manner in real life.

The obstacles, issues and problems that face these pre-service students need to be identified and resolved for the future implementation of PBL. The incorporation of PBL as a pedagogical instructional strategy in learning primary school science will assist curriculum designers in deciding whether to continue or discontinue the use of PBL as a tool in science learning.

PBL is a student-centred strategy for problem solving leading to the development of inquiry skills in a spirit of team work. Students learn at their own pace and therefore produce good results on completion of the project. The B.Ed. degree relies heavily on hands-on experience and practical work through PBL and the practicum.

Since it is a team effort, PBL needs to be researched to determine if the entire group was fully engaged in the learning and not only a few highly motivated and responsible individuals; the division of work among the group remains unquantified although some members may have heavier workloads. However, grades allocation is identical for each team member, irrespective of individual output. Depending on the effort made, not all members will have the same level of enhancement of the learning process. To determine student perceptions of PBL as a preferred approach to learning primary school science a questionnaire will be used. This questionnaire will test the overall satisfaction with the group experience and peer evaluation, group impact on quality learning and problem solving skills, professional development comprising the main operational activities of PBL (Parmelee, 2010).

These categories are the building blocks of PBL and the findings will clarify any ambiguities or misunderstanding surrounding this group-oriented pedagogical learning method for both students and practioners. Apart from the questionnaire this investigation of PBL will also involve semi-structured interviews to answer the three research questions.

The research problem is to look at the pre-service student teachers' perceptions of PBL as a pedagogical learning strategy that can be implemented as a learning instruction for primary school science. In PBL, the structure of the group and the role of the facilitator have a lot to do with its success or failure at the university or after graduation at the 
primary level. Student trainee teachers' perceptions and views in these implementation issues will yield vital information in the understanding of PBL as a learning strategy. It will be of great use to hear from students who learned through PBL how these issues of implementation impeded the process of learning and how they surmounted them.

\section{Review of the Literature}

The Problem Based Learning Method has been applied in the Medical and dental professions for over a quarter century. According to PBL Initiative-Southern University of Illinois (SIU) (n.d.) "PBL is a learner-centred educational method. In PBL, learners are progressively given more and more responsibility for their own education and become increasingly independent of the teacher for their education". (p.1). This type of learning strategy entails a great deal of hands-on, inquiry skills, critical thinking and problem solving. In PBL, there is a role shift from old banking system to the direct involvement of the student.

According to Greenwald (2000) "in PBL there is a shift in roles for students and teachers. The student, not teacher, takes primary responsibility for what is learned and how. The teacher is 'guide on the side" (p.2). This is one of the great merits of PBL since the child charts a course to him/herself in self directed learning. Ryan (1993) concludes that "students perceived SDL (Self Directed Learning) as important from the onset of the study. The students' perceived ability to perform SDL increased with the use of PBL..." (p.8)

PBL has also been adopted by engineers because it satisfies similar needs by the engineering profession. In the science field, scientists advocated inquiry based and discovery learning as being also hands-on methods. These methods are completely different from PBL because the student is not required to construct knowledge to solve the problem. The student will be provided with instructions to follow with all the required resources provided.

Since this study is geared to certain research questions pertaining to the pre-service teachers' perceptions in learning primary school science using PBL, the literature review will deal with the PBL in learning science and the perceptions of students about this learning strategy. This can be achieved through examining science learning in a group with the main feature of PBL as a learning tool because it is a form of collaborative learning in which group dynamics play a vital role in the learning process. The review will also seek to address the methodology that is appropriate to satisfy the aim of the study in gaining insight in the pre-service teachers' perceptions in learning primary school science using PBL as a learning strategy.

\section{Science Learning and PBL}

The mode of knowledge dissemination has been over the years in the hands of the teachers who deliver it in a manner that is passive to the learners. The entire learning process was based on rote and regurgitation followed by a summative examination for promotion to the next level of education. Being a scientist the researcher has been exposed to this old method of learning over the years and strongly agrees with the Constructivists who claim that students construct knowledge based on their previous one, hence hands-on and inquiry based learning are advanced as the means to achieve sound scientific knowledge.

The idea of studying student perceptions is a fairly new one because over the years the teachers and the instructors were the 'judge and jury' in matters of teaching and learning. The investigation of pre-service student trainee teachers' perceptions of learning science via the PBL method was long overdue. The intent in this research is to identify the overall perceptions of this strategy as a learning tool through gaining an insight in the perceptions of the pre-service teachers. The PBL has been characterized by Gallagher (1997) cited in Sonmez (2003) as:

The primary goal of $\mathrm{PBL}$ is characterized as learning for capability rather than learning to acquire knowledge. The effectiveness of PBL depends on the nature of student engagement and the culture of the classroom, as well as the appropriateness of the problem tasks assigned. Proponents of PBL believe that when students develop their own problem-solving procedures, they are integrating their conceptual knowledge with their procedural skills. (p.1).

In this statement, Gallagher is speaking about professional ability on the job and he is placing the effectiveness of the PBL pedagogical method of learning squarely on the student's actual engagement in the process of knowledge construction through PBL. It is the student's responsibility to construct the intended content knowledge and gain the hands-on experience. This is because of the change in the learning process from 'jug and mug' to 'self directed learning.' He noted the culture of the classroom which could mean that the old school method of teaching may cause an obstacle to implementing PBL. He also spoke about the choice of the problem to be researched whether it is 
appropriate for the student or not. Assigning the wrong problem may lead to poor learning and poor performance of the learner in the final assessment of the PBL.

Introducing PBL in the education system will be of great value to the young learners. Research has shown that "PBL resulted in: improved problem solving, improved time management, self learning, improved research skills..." (Bentley et al., 1999, p.1). These improvements are a great achievement for students who have undertaken PBL as a learning method. Because PBL entails a lot of planning and researching the relevant information, time management is very vital to the learner. There is also the ingredient of self directed learning (SDL) where the novice has to drive her/himself, at their own pace to acquire the desired information.

Since PBL advocates collaborative group learning and it takes five to six people to form a PBL group, the individual and the group input and their interaction has a lot to do with solving the problem.

\section{Group Learning in the PBL Method}

Group dynamics and group learning are the prime focus of the success or failure of using PBL as a learning strategy. This literature section responds to the second objective which is to examine pre-service teachers' perceptions of learning primary school science using the method of PBL. Here the group PBL is composed of five students. Knowledge of collaboration and group experience will add more to the understanding of the student's perception about PBL. Bauer, (2003) studying the qualitative assessment activities in PBL noted that:

Collaboration-given the collaborative nature of PBL students' perceptions are impacted upon by their group experiences, maintenance of functional group is essential. Under graduate peers tutors help monitor group dynamics and keep the groups on task... (p.6)

This statement will be tested against findings in the questionnaire which deals with the group and its dynamics in PBL. The overall group satisfaction and its impact on learning will be fully explored in the discussion of the questionnaire in the PBL group. Because of the nature of PBL as a group activity one cannot ignore the individual perceptions about working in a group to achieve a task that has a positive effect on the final grade.

In Australia Julie Clark (2004) outlined how to put the PBL strategy in the class room at the primary level. She found that:

Using this approach was more time consuming, less predictable and led to some unintended outcomes, but the major finding of our small group of teachers was that these disadvantages were compensated for by the enthusiasm and high levels of achievement of the students. (p.1)

In this case, although frustration prevailed, the levels of the students' achievement diffused the state of dismay and disappointment of the unpleasant unpredictable outcomes of PBL application.

\section{Methodology and Methods}

The methodology in this study will incorporate both quantitative and qualitative methods of inquiry because this project falls under the mixed methods paradigm in which a researcher seeks to gain an insight into the subjective domain of the participant whilst at the same time, collecting data that will quantify the responses given by the participants (Siwatu, 2011). The qualitative or interpretive method is described by Cohen et al (2007), as he advocates to the researcher to 'get inside the person and understand from within' (p.21). The rich descriptive narration given by the interviewee constitutes personal knowledge that is only shared with the researcher. This method of using interviews cannot be measured quantitatively or experimentally.

Since this research is based on the use of questionnaires also, the appropriate approach in this study therefore is a method that "must enable you to answer your research questions, and also to deal with plausible validity threats to these answers."'(Maxwell, 2008, p.216). Researchers formulate their questions either on variance or process. Maxwell (2008) further states that "variance questions deal with difference and correlation process questions, in contrast, focus on how and why things, happen, rather than whether there is a particular difference or relationship."(p.232)

It is clear then that when one is using semi-structured interviews, the questioning will follow the process type so that the desired answer can be obtained. This is due to the fact that in this type of research, one is not looking to measure the difference between two variables or the correlation between them quantitatively; therefore an ideal approach would also be a qualitative one. 


\section{Research Setting}

This research was conducted in an authentic setting at the University of Trinidad and Tobago, School of Cognition, Learning and Education, Corinth Campus, 2011. The student population who are engaged in the PBL at the primary science course are 94 students. The PBL constitutes $15 \%$ of the marks of the science course taught in this institution. It is widely used in most of the courses taught to pre-service teachers over the four year period of the B.Ed. Each discipline allocates the marks to PBL in relation to other means of assessment such as assignments and summative tests. The purpose of this research is to gain an insight into pre-service primary school teachers' perceptions of learning primary science using the method of Problem Based Learning (PBL).

Semi-structured interviews will be done with a $15 \%$ sample (5 participants) taken from thirty four (34) students. This sample will be drawn from among the third year cohort who has been exposed to PBL in their primary school science courses. Table 1 shows the demographics of the participants who were selected using purposive sampling. The selection was based on convenience and accessibility to the participants. The interview location is considered in the selection of these participants since the researcher was committed to pay the travelling expense. Moreover, these participants were more vocal and acquired good communication skills that made them worthy of selection by the researcher. Their task was to answer open ended questions that dealt with their past experiences in science learning perceptions about PBL of science and issues that were faced during this learning process.

The interview method was chosen because it allowed the participants to express their views freely without the researcher imposing choices on them as in a questionnaire. In addition, anonymous comments in writing were solicited from the participants for the purpose of triangulation (Maxwell, 2008), in patterns and themes. It is hoped that the information generated will yield the themes that will create the understanding of the research problem under investigation.

The choice of the participants in table (1) was based on the ability to communicate and give a clear response on answering the open ended questions in the semi-structured interview. It was a purposive sampling hence we are dealing with a qualitative research.

Table 1. Participant's Demographics

\begin{tabular}{lclllll}
\hline $\begin{array}{c}\text { Participants by } \\
\text { pseudonym }\end{array}$ & $\begin{array}{c}\text { Age } \\
\text { (Years) }\end{array}$ & Gender & Ethnicity & Education Level & $\begin{array}{c}\text { Number of } \\
\text { Years enrolled }\end{array}$ & $\begin{array}{c}\text { District of } \\
\text { Residence }\end{array}$ \\
\hline Participant 1 & 21 & Female & East Indian & Tertiary & Three (3) & Princes Town \\
Participant 2 & 27 & Male & East Indian & Tertiary & Three (3) & Rousillac \\
Participant3 & 19 & Female & East Indian & Tertiary & Three (3) & Couva \\
Participant4 & 21 & Female & East Indian & Tertiary & Three (3) & Rio claro \\
Participant5 & 37 & Female & East Indian & Tertiary & Three (3) & Gasparillo \\
\hline
\end{tabular}

This literature review outline was preceded by the introduction covering the main problem of the research which is the pre-service teachers' perceptions about learning primary school science using PBL as a learning method. The aim is to gain an insight into these perceptions of the pre-service teachers' learning primary school science using PBL. The main research questions were mentioned together with the objectives. A review of the literature pertaining to PBL, group dynamics and qualitative methodology was explored.

\section{Research Design}

The study used a case study approach which in reality gives the researcher an opportunity to be more focused and intense with the participants. According to Bell (2005) "the case study approach can be particularly appropriate for individual researchers because it provides an opportunity for one aspect of a problem to be studied in some depth..." (p.9). This method was chosen because it facilitated the observation and analysis of behaviours that were exhibited by students who were sampled in this research study. The case study approach because of the researcher's belief that the study objectives could be achieved and answers to the research questions could be obtained within the working environment. The easy access to the population which involved in PBL over three years was the main reason for this choice.

The data required for this kind of research is a mixed methods design. The student participants will describe their personal experiences and perceptions using their own words and expressions. This qualitative approach will aid in the development of information that could bring about themes and patterns for the data analysis. In this project also the 
sample was composed of five participants (table1) who expressed their views and perceptions in response to the research questions presented to them. A questionnaire was given to sixty (60) participants and only forty eight (48) responded.

\section{Sampling Procedure}

This study was conducted on one third year class of primary school science pre-service trainee teachers. The sample which participated in the semi-structured interviews research was taken from among thirty-four (34) students through the purposive sampling technique and not random sampling. According to Mann, (2004) a simple random sample is "a sample drawn in such a way that each element of the population has a chance of being selected is called a random sample..." (p.8). Purposeful sampling was chosen because of its convenience, cost effectiveness and ease of administration.

The participants of this project were composed of two groups from the third year cohort of the primary science class. One group of thirty-four (34) for the semi-structured interview purposive sample and another group that comprised the rest of the cohort were used for the questionnaire. The class of students for the semi-structured interview were chosen because they were immediately under the researcher's instructions at the time of sampling. They were briefed about the aims and objectives of this research study. They were told that participating in this project is optional and anyone with no intention to participate can withdraw before the sampling process began. Thereafter, the semi-structured interview group was selected by purposive sampling from thirty-four (34) students composed of one (1) male and thirty-three (33) females. A sample of five (5) students was taken because the PBL group is made up of a team of five students and that this sample represents $15 \%$ of the class. All students selected had experienced PBL during the three years in the B.Ed. programme at the institution where this research was conducted. This group comprised the 5 individuals with whom the semi-structured interviews were conducted.

The other group who participated in the questionnaire came from the body of the cohort where the questionnaire was distributed to them at random in different class rooms. Forty-eight (48) students out of sixty (60) responded to my questionnaire. The questionnaire was supervised by the instructor who had the class at the time of the administration of the instrument.

With respect to the five (5) who were sampled to be interviewed, a schedule was arranged with them at their convenience after they had read the information sheet and signed the consent form. Subsequently, the researcher met each one of them individually in the proposed secured venue at the institution's main building to conduct the interview. The room was serene and quiet and all the five (5) interviews were conducted without any disturbance. The interview varied between thirty-five (35) to forty-five (45) minutes and was audio recorded with the interviewees' permission. The participants were assured that their information would be confidential and would be reported anonymously. In the event of any publication they will also be informed of where to access it.

\section{Data Collecting Methods}

In collecting data this research adopted a mixed method approach. Two methods of data collections were used one was the semi-structured interviews followed by written comments and the other was a questionnaire (Adapted from Parmelee et al 2009, p.3). The semi-structured interviews followed by the open-ended questions allowed the participants to express their views and perceptions in a free and fair manner without any restrictions or interference from the interviewer. This type of interaction lends itself to providing very valuable information since the participant has the opportunity to elaborate in writing what he or she could not articulate through prompting by the interviewer.

The face to face interviews allowed the researcher to get to the root of the problem by asking questions and probing for further explanation or elaboration by saying "why" or "could you elaborate" or "explain." The five (5) participants were interviewed separately on their science experience, perceptions on PBL and issues faced during the process of learning science using PBL. The interview was audio recorded with the permission of the participants and later transcribed. Thereafter, the coding process was carried out in each interview transcript to identify themes. The interview sought to obtain answers to the three research questions. The main objective behind this was to give the participants the opportunity to speak freely about their early experience in science learning and in learning primary school science using PBL. They were also questioned about the issues that they faced during the process of learning through PBL.

The interviews were scheduled for 9 o'clock in the morning and at the availability and convenience of the participants. After the semi-structured interview was concluded, each participant was given a separate sheet of paper to write any 
comments they felt necessary to add to what was said in answering the research questions. Participants had no problem responding to the request for further information. These five written comments acted as an extra source of information complementing and triangulating the semi-structured interviews, and were very useful because they added to what have been spoken and recorded. Furthermore, it was done on the premise of anonymity for the participant to write anything that they felt uncomfortable speaking about in the interview.

These written comments in fact gave a deeper insight on the perceptions of the participants about PBL. The interviews were all administered by the researcher, and the questionnaire was administered by instructors who were conducting the class at the time of administering.

The transcription of the five interviews was a challenging task; however, it was well worth the effort since the information gathered was very fruitful and most appropriate to this type of research. The triangulation was also very useful as it added more dimensions to what had been recorded from the participant's interviews.

The questionnaire was used to gather specific information about the group dynamics in carrying out the PBL. It was analysed through a frequency distribution of the different response to the category of questions asked (Mann, 2004, p.30). Data were grouped into the following way 'agree' and 'strongly agree', 'disagree' and 'strongly disagree' and 'neutral.' Percentages of each group were arranged in tables for interpretation.

\section{Analysis and Findings}

In this section, the procedure followed to analyze data from the questionnaire and the semi-structured interviews will be discussed. Regardless of the methods of data collection, there are certain limitations to data interpretation. The limitations for this data collection will be identified and discussed after the procedure is outlined. The themes extracted from the results of the interviews and questionnaire will be presented in this section. Based on the premise that this research was done on a mixed methodology a great deal of quotations from the participants will be cited to lend support to the research findings.

\section{Procedure for Data Analysis}

The instruments used were a questionnaire and semi-structured interviews. Data from the questionnaire were analyzed according to grouping of responses on the five categories on a 1-5 Likert scale where specific questions were asked. The data from the interviews were transcribed, coded and analyzed according to the research objectives of gaining insight in the students' perceptions of learning primary school science using PBL as a teaching strategy. Categories and themes emerging from the analysis were identified for discussion.

\section{The Research Findings}

The results of the questionnaire were very specific as they were designed to answer certain questions pertaining to the process of the PBL as a group in action collaborating and deliberating to solve a problem. This has come about because the outcome of the PBL is totally dependent on the group dynamics and collaborative learning together with self directed learning (SDL). The responses of the five categories of questions answered are shown in Tables 2, 3, 4, 5, and 6.

\section{PBL Questionnaire Data Analysis}

Overall satisfaction of group experience (Table 2) is very important in PBL. In this questionnaire, 60\% agreed and strongly agreed that working with a group was a valuable experience. However, in some cases, other team members contributed more than others. In their experience, groups work together most of the time and team members respected each other as participants. This is in agreement with Bauer (2003, p.8/9) who stated, "several students emphasize that effective collaboration occurs when group members respect each other's abilities and viewpoints and trust that each member will do his or her share of the work". This is a positive perception taking into consideration only $16 \%$ disagreed and strongly disagreed. 
Table 2. Overall Satisfaction with Group Experience

\begin{tabular}{llll}
\hline & Frequency & Relative Frequency & Percentage \% \\
\hline Disagree/strongly disagree & 40 & 0.16 & 16 \\
Agree/strongly agree & 149 & 0.60 & 60 \\
Neutral & 59 & 0.24 & 24 \\
Total & 248 & 1.00 & 100 \\
\hline
\end{tabular}

Overall satisfaction with group impacts on learning (Table 3) showed 52\% agreed and strongly agreed whereas the $37 \%$ and $11 \%$ were neutral or disagreed, and strongly disagreed respectively. This is a strong indication that the learning process was not overwhelmingly satisfactory to the PBL participants. This can be explained in the sense that PBL is a self directed learning process that relies on the efforts of the individual learner. However, the $52 \%$ is an indicator that some participants have learned more content in courses which use PBL as a learning tool.

Table 3. Overall Satisfaction with Group Experience

\begin{tabular}{llll}
\hline & Frequency & Relative Frequency & Percentage \% \\
\hline Disagree/strongly disagree & 17 & 0.11 & 11 \\
Agree/strongly agree & 78 & 0.52 & 52 \\
Neutral & 55 & 0.37 & 37 \\
Total & 150 & 1.00 & 100 \\
\hline
\end{tabular}

Overall satisfaction with peer evaluation (Table 4) showed a closer trend to group impact on quality learning 55\% agreed and strongly agreed that they found that peer evaluation motivates them to work collaboratively as part of their group. They have also preferred peer evaluation as part of their group experience. However, $35 \%$ and $11 \%$ were neutral, disagreed or strongly disagreed, making peer evaluation not as popular as was expected. In fact, one of the responses on this subject in the semi-structured interview was in favour of lecturer rather than peer assessment:

"I think the lecturer should do everything they could. They wouldn't have any feeling or any relations with the students. They will only be more professional."

Table 4. Overall Satisfaction with Peer Evaluation

\begin{tabular}{llll}
\hline & Frequency & Relative Frequency & Percentage \% \\
\hline Disagree/strongly disagree & 16 & 0.11 & 11 \\
Agree/strongly agree & 82 & 0.55 & 55 \\
Neutral & 52 & 0.35 & 35 \\
Total & 150 & 1.00 & 100 \\
\hline
\end{tabular}

Group impact on problem solving (Table 5), 58\% agreed and strongly agreed that they found that being in a group helped them become better at problem solving. They also found that groups make the right decision and being part of a group discussion improved their ability to think through a problem. On the other hand, only $31 \%$ and $11 \%$ were neutral, disagreed or strongly disagreed respectively. This can be interpreted according to the group dynamics and the actual participation in the discussion and researching of the problem solution. A person who is a team player will do his or her utmost in contributing to the solution eventually he will gain satisfaction with a group on problem solving.

Table 5. Group Impact on Problem Solving Skills

\begin{tabular}{llll}
\hline & Frequency & Relative Frequency & Percentage $\%$ \\
\hline Disagree/strongly disagree & 16 & 0.11 & 11 \\
Agree/strongly agree & 89 & 0.58 & 58 \\
Neutral & 48 & 0.31 & 31 \\
Total & 153 & 1.00 & 100 \\
\hline
\end{tabular}


Professional development (Table 6) in this category, $80 \%$ agreed and strongly agreed that they found working with a group helped them to work with others and that working with a group helped them develop cooperative leadership skills. Furthermore, working with a group helped them develop more respect for the opinion of others and enhanced their sense of who they are. This category had the highest score since only $3 \%$ disagreed or strongly disagreed whereas $17 \%$ remained Neutral. This means that PBL is very effective in professional development in learning primary school science. This resonated with what Sonmez (2003) has described as: "The primary goal of PBL is characterized as learning for capability rather than learning to acquire knowledge" hence the reason PBL is popular among medics and dentist whose professions require team work.

Table 6. Professional Development

\begin{tabular}{llll}
\hline & Frequency & Relative Frequency & Percentage \% \\
\hline Disagree/strongly disagree & 6 & 0.03 & 3 \\
Agree/strongly agree & 162 & 0.8 & 80 \\
Neutral & 34 & 0.17 & 17 \\
Total & & 1.00 & 100 \\
\hline
\end{tabular}

In summary, the questionnaire results indicated that group satisfaction was positive while the impact of the group on learning was not overwhelming due to the nature of the self directed learning of PBL. The peer evaluation was found to be motivating by some but others prefer instructor assessment to avoid bias. The impact of the group on problem solving was positive since the participants agreed that it helped in problem solving. As for professional development $80 \%$ agreed or strongly agreed that it was a useful experience for them. From these results one can conclude that the second objective was achieved through the response of the questionnaire in that positive perceptions were expressed in learning primary science using PBL as a strategy. Looking at the semi-structured interviews the analysis was based on answering the three research questions through quotations from the five interviewees.

\section{Semi-Structured Interviews Data Analysis}

The results of the semi-structured interviews were analyzed as themes or categories responses for the first question: What are the pre-service teachers' early school experiences of learning science? The answer for this question showed the following patterns. All the participants spoke about lack of hands-on at the primary school but discovery and inquiry methods were encountered at the secondary level. The following are quotations from the five participants coded as I.D. 1-5

\section{(IDENTIFICTION)}

ID 1: "In the primary school we did not do much of experiments rather we did, we went home, created something and brought to class, but to do any kind of work within the classroom, we did not do any of that. In secondary school, however, we did some experiments and what not (sic), during integrated science."

This is a pedagogical constraint theme in which students were not exposed to constructivist methods rather they were taught through the old 'chalk and talk' and text books. This participant spelt out the 'chalk and talk' method and blamed the teaching methods on the limited resources of the school. This accounts for his poor science knowledge in both primary and secondary schools because integrated science at that level would not offer any solid science base for tertiary education.

ID 2: "Basically science in my time when I went I did more of a chalk and talk, we did not have much experiments and so on, because the primary school I went to, the resources were very limited at that point in time, the teachers, traditional way was use the text book which was integrated science textbook and we follow through."

Even at the secondary level, this participant's exposure to science was limited due to the nature of the junior secondary school in respect to science teaching. Here again can be seen the limited exposure to science learning with this participant and the reason some pre-service teachers had some difficulty in their B.Ed. science courses. "Basically I went to a junior secondary school before, we did not have science basically, as general science, we did, well like not in-depth science, we did basics, and experimentation was limited at that point too."

This participant admits that the teacher was more into theoretical delivery and not into discovery and inquiry methods which are the preferred ones in science learning. This is pedagogical deficiency on the part of the teacher who may have the content knowledge but lacks the appropriate strategy. 
ID 3: "The teacher did everything, at primary level and secondary level it was more theory not too much experiment outstanding and for project, yea, but more than practical stuff so to make any observations. I prefer the discovery, the inquiry method because you will be able to discover things on your own to see how stuff is happening instead of the teacher telling you. It was not attractive to me, I wasn't really into science, it was just boring, it was boring for me, may be if it was hands on, I might like it more, they just telling me, I will remember if I had done it myself."

It seems that these participants being mature adult students were exposed to different eras of primary and secondary science syllabi because a particular emphasis was put on Math, English and Social Studies while science was marginalized. This situation in the primary school impacted negatively on some student trainee teachers' content knowledge when they joined high school and proceeded to tertiary education. It can be concluded that they had unpleasant experiences that did not allow them to acquire solid foundation knowledge while learning science in their early days.

ID 4: "Yes we were not doing very much in terms of experiments it was not the focus of the syllabus, it was more a matter of do Math English, Social Studies was important, science was, a little by the way, it was not paid that much attention, more the Math and English. It was more demonstration and I remember doing some gardening work outside, little projects, little quiz, but not much, very little hands-on was done by students. Yes in a way at least when I was in secondary school we did some lab. work which is so different because I remember my teachers still taking us to the lab and we had a little work even so, it was not much, it was, may be three labs for the entire term, but it was very intriguing."

That learning science was an unpleasant experience at least at the primary level may be because of the pedagogical approach prevailed at that time, however, at the secondary level it seems to appeal to the students with the experimental approach. Some students got to appreciate and like learning science. This emphasizes that science learning has to be carried out through a variety of inquiry and discovery methods. It can be concluded from these participants' quotations that their past experience in learning science was unpleasant because of some issues such as lack of pedagogical training for teachers, limited resources in some schools and a policy that determined what subject was to be taught at the Common Entrance Examination.

ID 5: "Because in primary school, I was never interested in science, I never liked it, I don't know why and I just, when I started to do it in form one, straight until form three...I enjoyed it and I always had good marks, I always came in the top in the class of science. In form three we did an experiment with diffusion-Osmosis...they brought stuff in the class and showed us how to do it and how it works."

In summary, it can be said that the past experiences of the pre-service teachers in learning science was mainly due to the lack of pedagogical strategies for teaching science. Furthermore, the limited resources in both the primary and secondary schools particularly the Junior Secondary schools played a major role in the unpleasant experience that has been the outcome of their science learning. In one instance the experience was attributed to the emphasis put on learning Math, English and Social Sciences.

The second question of this project was: What are the pre-service teachers' perceptions of learning primary school science using the method of Problem Based Learning? Below are some quotations of the five participants: in the theme of PBL as a learning strategy (inquiry and discovery learning theme). There is a unanimous agreement among the participants that they prefer student centred strategies of teaching such as PBL and inquiry learning. These are their responses on PBL:

ID 1: "Definitely, I rather problem based learning, student centred rather than teacher centred especially for science, other subject as well."

ID 2: "PBL allows the teacher to give the students hands-on approach, give the students the control over their thoughts. Students are able to go out there and show the teacher how they understood...PBL will allow the child to explore. Yes I believe that, it is a very effective method, if used properly, it can be quite effective in science and in all areas."

ID 3: "To help them understand ... what to say, is for them to discover their own, have a hands-on approach, let them understand don't let it be ....... For them to cram it and cannot remember it after all the time."

ID 4: "As a teacher with the students I may not be required (to use PBL) on a curriculum sense, but I would prefer, I am trying to put it having used it and having been taught it as a strategy."

ID 5: "Yea, because - I think it is something required, because the PBL is problem Based Learning and from the problem that you give them, they learn from it and I think if you do that in the school it will be easier for them, they 
would understand, they would find it more attractive and want to do it. I think I would like to do it; it will be something that is necessary in the school."

The collaboration theme, generated as a result of group working with colleagues is a main feature of PBL. Bauer, (2003 p.10) in a PBL study, reported that "PBL prepares for a career later in life. It teaches you to work with others, to respect their ideas and listen to their opinions. This is an important skill because very rarely will you find a career where you don't have to interact with other people."

In this study, the questionnaire gave a clear picture about working with a group in that some students were satisfied with the group in problem solving and professional development. In this theme of collaboration, there are mixed perceptions as we can see below:

ID 1: "I can work with people to understand student but, may be different, I can speak about what might be the best method to do PBL for a certain topic...that is the most I could do with colleagues."

ID 2: "I like to consider myself as a team player mostly involved in group activities before, seen that I lead a lot of social groups outside there and in the school here, my peers gravitate towards me in groups."

The perception of working with a group could be a cause of conflict and different ideas were clearly articulated by ID 3 and ID 5 who seemed apprehensive about being a team player like ID 2. It is clear that working with class mates in PBL was a problem for some students. Holen (2000) cited in Edwards and Hammer (2007) identifying group issues in PBL stated that, "lecturers need to be sensitive to fluctuations in group dynamics rather than simply assuming that group participation will result in positive learning outcomes for the students" (p.488). To overcome this obstacle students are advised to choose a group that he/she can get along with during the PBL process.

ID 3: "May be, maybe not, I am not too sure when you work in groups it tends to have conflict and some people stick to their own way, than having your opinion being heard."

ID 5: "I, no, not really, I prefer work with myself, because, everyone has different ideas about everything and that way not to go ahead with my idea."

On the other hand, ID 4 attributes the willingness to work with colleagues on the school culture which sometimes may be hostile to things like PBL and group collaboration. This situation was also mentioned in the written comments which indicate that implementing PBL in the primary school setting may face some issues such as this one.

ID 4: "Once there is a willingness in the part of other colleagues, I have no problem working with people, but there is a culture in the schools right now that has to change and it is going to change very slowly."

The theme of applying PBL pedagogical method as a learning strategy has been articulated by the participants. It has been reported by Watter (2007) that implementing PBL in a pre-service teacher education programme "raised a number of pedagogical issues but paradoxically was effective in helping some students a deep approach to learning and enhanced confidence to teach science" (p.8). Seeing that PBL encourages directed self learning (DSL) and the students' constructing their own knowledge to solve a problem, the participants' responses were mixed but positive in enhancing their PCK to empower them to teach science using PBL learning strategy.

ID 1: "I am actually excited about using that because I get to sit down and think $O K$ what might be the best method for these children to be engaged in some type of learning."

ID 2: "Quite confident, I am a hands-on guy, I like to see group work I like to see action."

ID 3: "You actually do it yourself you sure that whatever thing taught you understand as a teacher and students understand it better, when you do it yourself when you teach it ...you help your confidence."

ID 4: "I need more experience trying it, I need some resources but I think it is more experience than anything else."

ID 5: "I would not say fully, like really, really confident, I am like in the middle, because, the only way I will be fully confident is if I know every single thing about that topic."

The theme of PBL and content knowledge construction showed very positive perceptions because of the directed self-learning approach that has to be undertaken along with the group members. Through researching the problem the trainee teacher will be well equipped to teach primary school science with the knowledge that has been gathered by $\mathrm{him} / \mathrm{her}$ and the group members. The nature of this acquired knowledge is more stable than what is achieved through formal lectures.

ID 1: "Yea, everything we have learnt we will need to do some part of it in the primary school, it may not be so indepth, we need to know more than the students." 
ID 2: "I did not look at it in- depth, the content will definitely help. Basically, it gives you a new outlook, what science is and how."

ID 3: "Content wise to help you understand the content because when you do like, on your own, you see there are also some things, and you understand the content better, and how to explain it to the students."

ID 4: "It was appropriate."

ID 5: "Yea, it actually taught me a lot because one thing I did not know before was about the seasons (PBL project), and how they occur...I did not know that at all, so if a student ask me about that now I will be able to teach them."

The theme fairness of PBL peer assessment was blamed on the members who do not pull their weight obtaining the same mark as the hard working ones. The participants were in favour of the lecturers handling the marking because they are unbiased and act professionally. Similar results were observed in the questionnaire where negative sentiments were expressed about peer assessment.

ID 1: "From experience, from doing PBL this semester, I can say that not everybody take part, not everybody has an equal part, somebody might have more than another, one person might have any at all, the assessment is not fair at all."

ID 3: "Some people might get the same amount of credit; people who are doing less work. I find that is unfair."

ID 5: "I think the lecturer should do everything they could. They wouldn't have any feeling or any relations with the students. They will only be more professional."

The third question of student perceptions was: what are the issues faced by pre-service teachers in learning primary science using the method of problem Based Learning?

The theme generated from this question is: The need for clear guidance to carry out the successful PBL task. This entails transparency between the facilitator and the group and his/her interaction with them together with full support till the end of the task. In this theme students felt that certain facilitators were clear whereas some gave ambiguous problems for students to solve taking a lot of effort to clarify and get on with the task.

ID 1: "In some part no. There were some questions we came up in our discussion in a lab after conducting an experiment, we not too clear of what to do. We have some problem there a time."

ID 2: "Generally we started to do PBL a little bit confused, that led us to going to the lecturer to find out what is to be done, and if we are in the correct path."

ID 3: "Yea, we were given enough instructions to follow, to know what to do correctly so we will get our marks. Yea, sufficient instructions were given about the research, step by step."

ID 4: "More so in the integrated science class because the integrated science classes are small, so we had a good rap with the lecturer."

ID 5: "Some (lecturers) gave it clear and some did not, because we had a lot of problems with other courses that we had to do. (The participant did not want to disclose the course but I assured her she could say anything). It was action research we had real problems with that."

The next theme discussed in the questionnaire was Group dynamics (Interaction). There were mixed reactions about working with a group, indicating that some groups which were homogeneously constructed from friends who hang around together would experience no friction. However, when the group was made of members who did not share the work load properly with one another friction and sensitivities occurred and confusion and chaos took over, as mentioned by ID 4.

ID 1: "We did everything together in school where we had access to everything. I did not have a problem working with the group."

ID 2: "It was quite simple, it is easy for you to go and find information, come together, come as a group and brings up information forward and you will have the analysis with the group."

ID 3: "Yeah, everyone was assigned to their part and there were no complaint, who had to do what, did their part. I did not have any problem working with the group; I was working with who I accustomed working with."

ID 4: "Sometimes work would fall more and more on one person, because they are able to get something done and it causes confusion and chaos some times, and people do fall out and people have their group clashes within themselves." 
ID 5: "No, we had no problem; because we always hang about together...None of us showed that we had a problem."

The group dynamic theme (interaction) is very well articulated here by the three participants; however, those who are in a friendlier group seem to enjoy a better camaraderie than those who are not friends. There is always an "odd man out" in each group but because it is a collective effort the lecturer has no means to detect or penalise a delinquent group member.

\section{Discussion of Findings}

The data presented in the previous section suggest a general consensus of agreement among the participants on a number of issues pertaining to the research questions. The perceptions of pre-service teachers about the early days of learning science were full of negativity and disappointment about the old methods of teaching. Most of them preferred an inquiry based or problem solving scientific method. In fact, some participants were 'turned off' from science learning completely because of the pedagogical approach undertaken by science teachers in primary school in those days.

Some of the participants argued that the lack of resources in both primary and secondary schools were the major obstacles between them and learning science through experimental and discovery methods. Some had a little exposure to such methods and it was rewarding and memorable. One of the participants blamed the lack of learning science on the great emphasis on the subjects of Math, English and Social Sciences. This has been a problem for decades in primary level science because the Ministry of Education removed science from its Secondary Entrance Examination. Teachers were more concerned about teaching common entrance subjects than science.

One participant was very explicit in her views about learning science when she said, "it was not attractive to me, I wasn't really into science, it was just boring, it was boring for me, may be if it was hands on, I might like it more."

This is strong evidence showing how pre-service teachers were discouraged from learning science very early and they knew that the best way of learning is the 'hands-on' methods such as PBL and inquiry based learning.

In their response to the question: 'What are the pre-service teachers' perceptions of learning primary school science using the method of Problem Based Learning', the answers given by the participant generated a number of themes. These included PBL enhanced content knowledge, group learning and team players, confidence in teaching from knowledge gained through PBL, increased content knowledge due to (SDL) and group interaction, the fairness of PBL assessment was not favoured because of group dynamics, the time allocation for PBL was sufficient however time for its application in the primary school is not enough.

In the third study question about issues faced, the participants were not happy with the clarity of instructions for PBL with certain subject matter instructors. The issue of transparency with including PBL without consulting the student was raised. This is due to the fact that assessment of PBL is based on the product of the whole group. It follows that the hard working members receive the same marks as the 'free riders.' This led to mixed reaction in working with a group. In a similar study, this matter was raised by PBL participants:

Many students expressed strong concern about group members who demonstrate a lack of commitment to the group. This lack of commitment is evidenced by irregular attendance, unpreparedness, unreliability, disinterest, lack of motivation, and incomplete work. According to one student, "We consistently have two people missing from our four-person group."(Bauer, 2003, p.10). This appears to be one be one of the weaknesses of the structure of the PBL and would lead to disunity.

The findings of this research are similar to what has been reported in the literature in that the perceptions about PBL are positive. In this study, the pre-service trainee teachers used very simple language to express their views about PBL. They delved into a lot on the group and collaborative work and how the group could organize itself. There was no time constraint for completing PBL; however there was a misconception about the application of PBL in the primary school due to the length of the class period set for only thirty (30) minutes.

The negative perception of group assessment came about because in this institution most of the courses were done through individual assignments. The combination of the assignments and the summative final examination marks determine the ability of a person who could rote and regurgitate rather than a critical thinker.

I believe that one of the major issues the students faced is that they were unhappy about the assessment criteria of PBL for the group as a whole. It is obvious that in any group work some members contribute more while others input is meagre. The concern about group assessment has always appeared to be one strong perception about PBL in allocating 
marks. This is because the marking scheme does not take into consideration the amount of individual work load and commitment to the group.

The assessment of the PBL product alone should not be the final mark. To correct this dilemma, oral presentation should be introduced and each individual in the group is assessed alone. This will provide an edge to the student who contributed positively in the PBL learning process. One would appreciate how difficult it would be for an instructor to determine the level of productivity from a finished product with five (5) or six (6) authors.

The results of this study show that PBL as a learning pedagogical strategy is well accepted by pre-service trainee teachers; however the negative perception about fairness in the assessment scheme for the group needs to be addressed by the proponents of PBL in science teaching.

The participants' comments in the triangulation question should also be taken into consideration, particularly what was said about the school culture for implementing new pedagogical strategies such as PBL. Additionally, the use and abuse of PBL when implemented has to be carefully monitored through clear guidelines. The student consultation in assessment tools such as PBL should also be examined. The participants felt that PBL should not be confined to science alone but its administration in the art subjects is also worthwhile.

The students' experience in learning science at the primary level was more or less similar in pattern; in that the 'chalk and talk' was the dominant method of teaching. This had a negative impact on their likeness for science. However, at the secondary level, more hands on and discovery methods were experienced which erased the stigma about science learning for some of them.

The students' perceptions about learning science through the PBL strategy were positive for both group and individual. They believed they could apply PBL with confidence in their future teaching, provided the school culture and the resources issues are resolved.

The most common issues which arose were group interaction and group assessment, and facilitators' role. Perceptions about working with a group were evident where members of the group felt some had more input than others. This situation resulted in the perception of unfair assessment at the end of the PBL. Additionally, negative perceptions about peer assessment were expressed and it was suggested that the lecturer should be responsible for this task. The role of the facilitator for giving clear instruction was also noted. The literature review has shown similar themes of these perceptions. Generally, students wanted transparency in the instructions of PBL because in some instances they were completely lost and knew nothing of what is required.

The group dynamic results obtained from the questionnaire were most outstanding where students perceived positive satisfaction with the group experience. They also generally agreed on professional development and problem solving through PBL.

The results of this study cannot help in any generalization of the given results; however, it invites further investigations with a bigger sample size. The results also suggest a longitudinal study could be done with these graduates when they are placed in different primary schools and analyze their application of PBL in their primary school science teaching. This will give an indication of whether their perceptions have changed or if they held on to it and managed to 'beat the system' by applying what they learnt about PBL as a learning strategy in primary school science.

This research has provided a great opportunity to understand the perceptions of third year primary science students in PBL, a tool which the researcher always uses in science instructions. It was learnt that student perceptions and previous knowledge are vital to the construction and implementation of scientific knowledge particularly when PBL is used as a learning pedagogical strategy.

The results of this research study may not be overwhelming due to certain limitations such as the sample size and researcher bias; however, they contributed to the volume of knowledge in determining the positive perceptions of pre-service trainee teachers in learning primary school science with PBL. This will afford them the opportunity to apply it when they become fully fledged teachers with the Ministry of Education.

\section{Recommendations}

1. A similar study could be conducted with a bigger sample size for the different subjects that use PBL to determine its validity as a learning strategy and an assessment tool since students' perceptions about group and peer assessment was negative.

2. A longitudinal follow up research should be initiated to follow this cohort who learned primary science through PBL. This research objective would be to determine whether these graduates were able to apply what they learnt through 
PBL or was their failure due to certain contextual settings as mentioned by the participant re: 'the school culture'.

3. For application of PBL as a learning strategy, resources have to be made available to the students with clear transparency and guidance by the facilitators who are to be the 'guide on the side' if they are to be effective.

\section{Conclusion}

The results of this study show that PBL as a learning pedagogical strategy is well accepted by pre-service trainee teachers; however the negative perceptions about fairness in the assessment scheme for the group need to be addressed by the proponents of PBL in science teaching. Furthermore, the use and abuse of PBL when implemented has to be carefully monitored through clear guidelines. The student consultation in assessment tools such as PBL should also be examined. The participants felt that PBL should not be confined to science alone but administering it in the Arts, is also worthwhile.

\section{References}

Bauer, G. (2003). Qualitative Assessment Activities for Pew Grant on Problem-Based Learning (PBL). Retrieved April 27, 2011 from www.udel.edu/pbl/Final-Report-Pew-PBL.pdf

Bell, J. (2005). Doing your Research Project: a guide for first-time researchers in education, health and social science $\left(4^{\text {th }}\right.$ ed.). England: Open University Press.

Bentley J. F., Lowry G. R., \& Sandy G. A. (1999). Towards the Compleat Information Systems Graduate: A Problem Based Learning Approach .Proc. 10th Australian conference on Information Systems, 1999. Retrieved April 27, 2011 from academic.research.microsoft.com/Paper/460929

Clark, J. (2004). Leaving the primary comfort zone. Talking Science. Spring 2004. [Accessed 22nd July 2011]

Cohen, L., Manion, L., \& Morrison, K.R.B. (2007). Research Methods in Education (6 ${ }^{\text {th }}$ ed.). New York: Routledge.

Edwards, S., \& Hammer, M. (2007). Problem based learning in early childhood and Primary pre-service teacher education: identifying the issues and examining the benefits. Australian Journal of Teacher Education, 32(2), 21-36. http://dx.doi.org/10.14221/ajte.2007v32n2.3

Freire, P. (1970). Pedagogy of the oppressed. New York: Seaburg Press.

Gallagher, S.A. (1997). Problem-based learning; Where did it come from .what does it do and where is it going? Journal for the Education of the gifted, 20(4), 332-362.

Greenwald, N. (2000). Learning from problems. The Science Teacher, 67(4), 28-34.

Holen, A. (2000). The PBL group: self-reflections and feedback for improved learning and growth. Medical Teacher, 22(5), 485-488. http://dx.doi.org/10.1080/01421590050110768

Mann, P.M. (2004). Introductory Statistics (5th ed.). USA: John Wiley \& Sons, Inc.

Maricopa, (n.d.) (2011). Problem Based learning. Retrieved April 27, 2011 from http://www.mcli.dist.maricopa.edu/pbl

Maxwell, J.A. (2008). Designing a Qualitative Study. Retrieved April, 27, 2011 from http://www.sagepub.com/upm-data/23772_ch7.pdf

Minner, D. D., Levy, A. J., \& Century J. (2010). Inquiry-based science instruction what is it and does it matter? Results from a Research synthesis Years 1984 to 2002. Journal of Research in Science Teaching, 47(4), 474-496. http://dx.doi.org/10.1002/tea.20347

Napoli, R. Di. (2004). What is Student Centred Learning? Retrieved April 27, 2011 from www.westminster.ac.uk/_data/assets/pdf_file/0004/41782/StudentCentred Learning.pdf

Parmelee, D.X., De Stephen D., \& Borges N.J. (2009). Medical students' attitudes about team-based learning in a pre-clinical curriculum. Medical Education Online, 14(1), 1-7. http://dx.doi.org/10.3885/meo.2009.Res00280

PBL (2003). Problem Based Learning Initiative-Southern Illinois University School of Medicine PBL. Retrieved April 27, 2011 from http://www.pbli.org/pbl/pbl.htm

Ryan, G. (1993). Student perceptions about self-directed learning in a professional course implementing problem-based learning. Studies in Higher Education, 18, 53-64. http://dx.doi.org/10.1080/03075079312331382458 
Siwatu, K.O. (2011). Pre-service teachers' culturally responsive teaching self-efficacy-forming experiences: a mixed methods study. The Journal of Educational Research, 104(5), 360-369. http://dx.doi.org/10.1080/00220671.2010.487081

Sonmez, D-Lee, H. (2003). Problem-Based Learning in science. ERIC Clearinghouse for Science Mathematics and Environmental Education, Columbus OH. Retrieved 27th April 2011 from www.vtaide.com/png/ERIC/PBL-in-Science.htm

Walker, J.T., \& Lofton, S. P. (2003). Effect of a problem based learning curriculum on students' perceptions of self directed learning. Issues in Educational Research, 13, 1-22.

Watters, J. J. (2007). Problem Based Learning in pre-service elementary science teacher education: Hostile territory. In Proceedings PBL Conference on Problem -Based Learning in Undergraduate and Professional education, October 29-31, 2007, Birmingham Alabama. 